\title{
Mitral-Valve Repair versus Replacement for Severe Ischemic Mitral Regurgitation
}

\author{
Michael A. Acker, M.D., Michael K. Parides, Ph.D., Louis P. Perrault, M.D., Alan J. \\ Moskowitz, M.D., Annetine C. Gelijns, Ph.D., Pierre Voisine, M.D., Peter K. Smith, M.D., \\ Judy W. Hung, M.D., Eugene H. Blackstone, M.D., John D. Puskas, M.D., Michael \\ Argenziano, M.D., James S. Gammie, M.D., Michael Mack, M.D., Deborah D. Ascheim, M.D., \\ Emilia Bagiella, Ph.D., Ellen G. Moquete, R.N., T. Bruce Ferguson, M.D., Keith A. Horvath, \\ M.D., Nancy L. Geller, Ph.D., Marissa A. Miller, D.V.M., Y. Joseph Woo, M.D., David A. \\ D’Alessandro, M.D., Gorav Ailawadi, M.D., Francois Dagenais, M.D., Timothy J. Gardner, \\ M.D., Patrick T. O'Gara, M.D., Robert E. Michler, M.D., and Irving L. Kron, M.D. ' for the \\ CTSN
}

\begin{abstract}
Background-Ischemic mitral regurgitation is associated with a substantial risk of death. Practice guidelines recommend surgery for patients with a severe form of this condition but acknowledge that the supporting evidence for repair or replacement is limited.

Methods-We randomly assigned 251 patients with severe ischemic mitral regurgitation to undergo either mitral-valve repair or chordal-sparing replacement in order to evaluate efficacy and safety. The primary end point was the left ventricular end-systolic volume index (LVESVI) at 12 months, as assessed with the use of a Wilcoxon rank-sum test in which deaths were categorized below the lowest LVESVI rank.
\end{abstract}

\begin{abstract}
Results-At 12 months, the mean LVESVI among surviving patients was $54.6 \pm 25.0 \mathrm{ml}$ per square meter of body-surface area in the repair group and $60.7 \pm 31.5 \mathrm{ml}$ per square meter in the replacement group (mean change from baseline, -6.6 and $-6.8 \mathrm{ml}$ per square meter, respectively). The rate of death was $14.3 \%$ in the repair group and $17.6 \%$ in the replacement group (hazard ratio with repair, $0.79 ; 95 \%$ confidence interval, 0.42 to $1.47 ; \mathrm{P}=0.45$ by the log-rank test). There was no significant between-group difference in LVESVI after adjustment for death ( $\mathrm{z}$ score, $1.33 ; \mathrm{P}=$ 0.18 ). The rate of moderate or severe recurrence of mitral regurgitation at 12 months was higher in the repair group than in the replacement group ( $32.6 \%$ vs. $2.3 \%, \mathrm{P}<0.001)$. There were no significant between-group differences in the rate of a composite of major adverse cardiac or cerebrovascular events, in functional status, or in quality of life at 12 months.
\end{abstract}

\footnotetext{
Copyright (C) 2013 Massachusetts Medical Society.

Address reprint requests to Dr. Gelijns at the Department of Health Evidence and Policy, Icahn School of Medicine at Mount Sinai, 1 Gustave L. Levy Pl., Box 1077, New York, NY 10029, or at annetine.gelijns@ mssm.edu.

The authors' affiliations are listed in the Appendix.

${ }^{*}$ A list of members of the Cardiothoracic Surgical Trials Network (CTSN) is provided in the Supplementary Appendix, available at NEJM.org.

Disclosure forms provided by the authors are available with the full text of this article at NEJM.org.
} 
Conclusions-We observed no significant difference in left ventricular reverse remodeling or survival at 12 months between patients who underwent mitral-valve repair and those who underwent mitral-valve replacement. Replacement provided a more durable correction of mitral regurgitation, but there was no significant between-group difference in clinical outcomes. (Funded by the National Institutes of Health and the Canadian Institutes of Health; ClinicalTrials.gov number, NCT00807040.)

Functional ischemic mitral regurgitation affects 1.6 million to 2.8 million patients in the United States and is associated with a doubling in mortality among patients with mild or greater degrees of mitral regurgitation after myocardial infarction. ${ }^{1-3}$ Ischemic mitral regurgitation is a consequence of adverse left ventricular remodeling after myocardial injury with enlargement of the left ventricular chamber and mitral annulus, apical and lateral migration of the papillary muscles, leaflet tethering, and reduced closing forces. These processes lead to malcoaptation of the leaflets and variable degrees of mitral regurgitation that can fluctuate dynamically as a function of volume status, after-load, heart rhythm, and residual ischemia. The leaflets themselves are normal, and the disease occurs in the myocardium rather than in the valve itself. As such, the treatment of functional ischemic mitral regurgitation differs considerably from that of primary, degenerative mitral regurgitation. ${ }^{4}$

Practice guidelines recommend consideration of mitral-valve repair or chordal-sparing replacement for patients with severe ischemic mitral regurgitation that is causing limiting symptoms despite the best available medical therapy and, possibly, cardiac resynchronization. ${ }^{5,6}$ These guidelines, however, do not specify whether to repair or replace the mitral valve, because conclusive evidence is lacking to indicate which of these interventions is superior. Clinical studies have suggested that repair is associated with lower perioperative mortality, ${ }^{7-10}$ whereas replacement provides better long-term correction with a lower risk of recurrence (an important consideration, since recurrence of mitral regurgitation confers a predisposition to heart failure, atrial fibrillation, and readmission). This perceived tradeoff between reduced operative morbidity and mortality with repair and better long-term correction of ischemic mitral regurgitation with replacement has generated substantial variation in surgical practice for this high-prevalence condition. ${ }^{4}$

The Cardiothoracic Surgical Trials Network (CTSN) conducted a multicenter, randomized trial to evaluate the relative benefits and risks of repair versus replacement, with or without coronary revascularization, in patients with severe ischemic mitral regurgitation.

\section{Methods}

\section{Study Design and Oversight}

We randomly assigned patients with chronic, severe ischemic mitral regurgitation, in a 1:1 ratio, to undergo either mitral-valve repair or chordal-sparing replacement. The randomization was stratified according to center and blocked to ensure ongoing equivalence of group size. The trial was designed to enroll 250 patients; 1 additional patient underwent randomization before the completion of enrollment. Investigators were unaware of overall 
outcome data. End points were measured at 30 days and at 6, 12, and 24 months; the 24month follow-up is ongoing.

The trial was conducted at 22 clinical centers, with a coordinating center, an independent committee that adjudicated causes of death and adverse events, and a data and safety monitoring board, appointed by the National Institutes of Health, that oversaw trial progress. The institutional review board at each study center approved the protocol, which is available with the full text of this article at NEJM.org. All patients provided written informed consent.

\section{Patients}

The target population was adults with severe ischemic mitral regurgitation and coronary artery disease who were eligible for surgical repair or replacement of their mitral valves, with or without coronary-artery bypass grafting (CABG). Severe ischemic mitral regurgitation was assessed by means of resting transthoracic echocardiography on the basis of integrative criteria ${ }^{11}$ that were verified by an independent core laboratory. Severe mitral regurgitation was defined as an effective regurgitant orifice area of $0.4 \mathrm{~cm}^{2}$ or more. If the effective regurgitant orifice area was less than $0.4 \mathrm{~cm}^{2}$, the assessment of the severity of mitral regurgitation was guided by associated findings, including the ratio of the jet area to the left atrial area, the width of the vena contracta, the density of the continuous-wave Doppler profile of mitral systolic function, the pulmonary-vein systolic flow pattern, and left-sided chamber dimensions.

Exclusion criteria included any echocardiographic evidence of structural (chordal or leaflet) mitral-valve disease or ruptured papillary muscle. Complete eligibility criteria have been reported previously. ${ }^{12}$

\section{Interventions}

Mitral-valve replacement included complete preservation of the subvalvular apparatus. The technique of preservation, type of prosthetic valve, and technique of suture placement were chosen according to the preference of the surgeon, as was the type of annuloplasty ring in the repair group. The protocol mandated the use of an approved rigid or semirigid complete annuloplasty ring, which was downsized for the annulus diameter. All patients were to receive guideline-directed medical therapy by their treating cardiologist, including aspirin, lipid-lowering agents, beta-blockers, and angiotensin-converting-enzyme inhibitors, as well as cardiac-resynchronization therapy.

\section{End Points}

The primary end point of the trial was the degree of left ventricular reverse remodeling, as assessed by means of the left ventricular endsystolic volume index (LVESVI) on the basis of transthoracic echocardiography performed 12 months after randomization. The LVESVI was verified by the echocardiography core laboratory. Secondary end points included mortality, a composite of major adverse cardiac or cerebrovascular events (rate of death, stroke, subsequent mitral-valve surgery, hospitalization for heart failure, or an increase in New York Heart Association [NYHA] class of $\geq 1$ ), serious adverse events, recurrent mitral regurgitation, quality of life, and rehospitalization. 


\section{Statistical Analysis}

The trial was designed with a power of $90 \%$ to detect a between-group difference of $15 \mathrm{ml}$ per square meter in the LVESVI from baseline to 12 months. We assumed a baseline LVESVI of $100 \mathrm{ml}$ per square meter, improvements of $20 \mathrm{ml}$ per square meter in the repair group and $35 \mathrm{ml}$ per square meter in the replacement group, and equal 1-year mortality of 10 to $20 \%$ in the two groups. ${ }^{13-15} \mathrm{We}$ planned one interim analysis using a group-sequential monitoring procedure with a Lan-DeMets stopping boundary and O'Brien-Fleming spending function. ${ }^{16,17}$ The primary null hypothesis was that there would be no betweengroup difference in the LVESVI at 12 months. We tested this hypothesis in an intention-totreat analysis using a two-tailed Wilcoxon rank-sum test, at a 0.05 alpha level. This analysis accommodated nonignorable missing LVESVI outcomes owing to the death of patients by assigning deceased patients the worst ranks in order on the basis of the time of death. We used multiple imputation for data that were missing for reasons other than death to calculate the 12-month LVESVI on the assumption that the data were missing at random. We used the Hodges-Lehmann estimator to quantify between-group differences in the reduction of the LVESVI from baseline. Sensitivity analyses assessed the robustness of findings to protocol deviations, missing data, and mortality (for adjustment to the LVESVI).

We used the log-rank test to compare rates of major adverse cardiac or cerebrovascular events and death from any cause and used hazard ratios from Cox regression models to quantify relative risks. Poisson regression was used to test between-group differences in rates of adverse events. We used chi-square tests to compare between-group differences in functional status (NYHA and Canadian Cardiovascular Society classifications). We used the Minnesota Living with Heart Failure questionnaire and the physical and mental subscales of the Medical Outcomes Study 12-Item Short Form Health Survey (SF-12) to assess quality of life. We used t-tests to compare differences in mean quality-of-life scores among surviving patients at 12 months.

\section{Results}

Patients

From 2009 through 2012, we screened 3458 patients; 447 of these patients were eligible to participate in the study, and 251 underwent randomization (126 to mitral-valve repair and 125 to mitral-valve replacement) (Fig. S1 in the Supplementary Appendix, available at NEJM.org). The two groups had similar baseline characteristics (Table 1). The mean ( \pm SD) LVESVI was $61.1 \pm 26.2 \mathrm{ml}$ per square meter in the repair group and $65.7 \pm 27.4 \mathrm{ml}$ per square meter in the replacement group $(\mathrm{P}=0.17)$. The echocardiography core laboratory confirmed the diagnosis of severe mitral regurgitation in $96 \%$ of the patients; the remaining $4 \%$ of the patients had moderate mitral regurgitation. The use of anti-ischemic medications and heart-failure therapies was similar in the two study groups.

Concomitant procedures were performed in $86.1 \%$ of the patients. Investigators used complete annuloplasty rings in all patients undergoing mitral-valve repair, with an average ring size of $28.4 \pm 1.9 \mathrm{~mm}$ for men and $27.2 \pm 1.6 \mathrm{~mm}$ for women. Among patients receiving valve replacements, $95.4 \%$ underwent a chordal-sparing procedure. Because of 
intraoperative complications 11 patients in the repair group underwent valve replacement, and 1 patient in the replacement group underwent repair.

\section{Left Ventricular Dimension and Function}

At 12 months, the mean LVESVI among surviving patients was $54.6 \pm 25.0 \mathrm{ml}$ per square meter in the repair group and $60.7 \pm 31.5 \mathrm{ml}$ per square meter in the replacement group (mean change from baseline, $-6.6 \mathrm{ml}$ and $-6.8 \mathrm{ml}$ per square meter, respectively). The rate of death was $14.3 \%$ in the repair group and $17.6 \%$ in the replacement group (hazard ratio with repair, $0.79 ; 95 \%$ confidence interval [CI], 0.42 to $1.47 ; \mathrm{P}=0.45$ by the log-rank test). The rankbased assessment of LVESVI at 12 months after adjustment for death showed no significant between-group difference ( $\mathrm{z}$ score, $1.33 ; \mathrm{P}=0.18$ ). The median between-group difference in the change in the LVESVI from baseline was only $2.1 \mathrm{ml}$ per square meter $(95 \% \mathrm{CI},-5.1$ to 9.3), which ruled out any clinically relevant difference. The mean left ventricular ejection fraction at 12 months was $41.5 \pm 10.8 \%$ in the repair group and $37.8 \pm 12.5 \%$ in the replacement group.

The proportion of surviving patients with a recurrence of moderate or severe mitral regurgitation at 12 months was significantly higher in the repair group than in the replacement group (32.6\% [ $28.4 \%$ moderate and $4.2 \%$ severe] vs. $2.3 \%$ [all moderate]; $\mathrm{P}<0.001)$. In the repair group, the 12-month LVESVI was $64.1 \pm 23.9 \mathrm{ml}$ per square meter in patients with recurrent mitral regurgitation versus $47.3 \pm 23.0 \mathrm{ml}$ per square meter in those without recurrent mitral regurgitation $(\mathrm{P}<0.001)$. Within 1 year, three patients in the repair group and none in the replacement group underwent mitral-valve reoperation $(\mathrm{P}=0.25)$.

\section{Death and Composite Cardiac End Point}

At 12 months, we observed no significant difference in cumulative mortality between the repair group and the replacement group (hazard ratio, $0.79 ; 95 \%$ CI, 0.42 to 1.47 ). The $30-$ day rate of death was $1.6 \%$ in the repair group ( 2 deaths) and $4.0 \%$ in the replacement group (5 deaths). Between 30 days and 1 year, 33 additional deaths occurred and were evenly distributed between the two study groups (Fig. 1A). The most frequent primary causes of death were multisystem organ failure (37.5\%), heart failure (12.5\%), and renal failure $(10.0 \%)$. At 12 months, there was no significant between-group difference with respect to the composite end point of major adverse cardiac or cerebrovascular events (hazard ratio, $0.91 ; 95 \% \mathrm{CI}, 0.58$ to $1.42 ; \mathrm{P}=0.68$ by the $\log$-rank test) (Fig. 1B) or any of its individual components (Table 2).

\section{Adverse Events and Hospitalization}

Rates of serious adverse events - most frequently, heart failure, arrhythmias, major localized infection, and respiratory failure - did not differ significantly between the two study groups at 1 year (Table 2). The duration of the index hospitalization was similar in the repair and replacement groups (mean, 17.3 \pm 11.4 days and $16.7 \pm 10.4$ days, respectively; $\mathrm{P}=$ 0.84 ; and median, 14 days in each group). The mean length of stay after surgery was $11.5 \pm 9.0$ days in the repair group and 11.9 \pm 8.6 days in the replacement group, with no significant between-group differences in rates of readmission. 


\section{Quality of Life}

There was no significant difference between the two study groups with respect to any measure of quality of life or functional status at 12 months (Table 3). As measured on the Minnesota Living with Heart Failure questionnaire, there was a reduction from baseline in heart-failure symptoms of $46.9 \%$ in the repair group and $61.2 \%$ in the replacement group. Similarly, as measured by means of the score on the SF-12 physical subscale, there was improvement over baseline in physical health of $16.6 \%$ in the repair group and $18.4 \%$ in the replacement group. Figure 2 shows NYHA classification and mortality over time.

\section{Discussion}

The most effective surgical approach to the treatment of severe ischemic mitral regurgitation remains controversial. In the past few years, the use of mitral-valve repair has greatly exceeded the use of replacement. ${ }^{18}$ However, no randomized trials have established the superiority of repair across a spectrum of patients with severe ischemic mitral regurgitation.

Left ventricular remodeling, as measured by means of the LVESVI (the primary end point in our trial), is a predictor of poor prognosis among patients with ischemic myocardial disease, and efforts to reverse such remodeling have been associated with improved outcomes. ${ }^{19-21}$ In our study, the two surgical approaches reduced the LVESVI at 12 months, although there was no significant between-group difference. Moreover, there were no significant differences in mortality at 30 days or 12 months. The observed 30-day rates of death (1.6\% in the repair group and $4.0 \%$ in the replacement group) were lower than the national rates reported by the Society of Thoracic Surgeons (5.3\% and $8.5 \%$ for repair and replacement with CABG, respectively). ${ }^{22}$

Our findings contradict much of the published literature on this topic, which reports several advantages to mitral-valve repair over replacement, including lower operative mortality, improved left ventricular function, and higher rates of long-term survival. ${ }^{23-26}$ In particular, in a recent meta-analysis, ${ }^{27}$ the relative long-term risk of death was $35 \%$ higher in the replacement group than in the repair group. Patients undergoing mitral-valve replacement tend to be older and have more coexisting illnesses than those undergoing repair, so adjustment for baseline differences has been critical in nonrandomized studies. Yet even these methods cannot adjust for differences when particular risk factors are unknown or unmeasured, which may explain why some studies have shown no differences in short-term or long-term rates of survival between repair and replacement groups ${ }^{28}$ whereas a majority of studies have favored repair. The evolution of valve replacement with chordal sparing may account for the improved results we observed, as compared with previous studies, since the retention of the internal architectural support of the left ventricle may preserve contractile efficiency and reduce left ventricular dilatation and dysfunction.

Our trial confirmed an excess incidence of recurrence of mitral regurgitation at 1 year among patients undergoing mitral-valve repair. Among survivors, the rate of moderate or severe recurrent mitral regurgitation at 1 year was 30 percentage points higher among patients who underwent repair than among those who underwent replacement. Our findings are similar to those reported in previous studies, in which the 6-month prevalence of mitral 
regurgitation of $2+$ or more after repair was 15 to $25 \%$ and increased substantially over time. ${ }^{29,30}$ The patients with recurrence in the repair group showed no reverse remodeling, as compared with those without recurrence (LVESVI of $64.1 \pm 23.9$ and 47.3 \pm 23.0 , respectively). This lack of durability in correction of mitral regurgitation is disconcerting, given its reported association with further progression and long-term negative outcomes. ${ }^{4,31,32}$

The high rate of recurrence of mitral regurgitation in the repair group did not correspond with significant differences in the overall composite end point of major adverse cardiac or cerebrovascular events, quality of life, or functional status at 12 months. Similarly, rates of serious adverse events and hospital readmissions did not differ significantly between groups.

The baseline LVESVI that we observed was lower than we had assumed it would be, reflecting variability in left ventricular size and severity of mitral regurgitation in these patients, along with inconsistent methods that were used to assess mitral regurgitation in previous studies. Although the baseline LVESVI was lower than assumed, so too was its variability, with the statistical power for the study remaining at $90 \%$. The mitral regurgitation in patients enrolled in this trial was entirely ischemic in nature and was severe (in $96 \%$ of the patients) according to integrative echocardiographic criteria, and the baseline ejection fraction was similar to that reported previously. ${ }^{33}$ The mean effective regurgitant orifice area among patients in our study was $0.4 \mathrm{~cm}^{2}$, which qualifies as severe mitral regurgitation according to the recent guidelines of the European Society of Cardiology, which provide a threshold of $0.2 \mathrm{~cm}^{2}$. The patients in our study had a relatively long length of stay during the index hospitalization, with the majority of the stay occurring after surgery. This duration may reflect the patients' relatively high rates of respiratory failure, bleeding, and supraventricular arrhythmia in the first 30 days, complications that provide targets for quality-improvement measures.

Our trial has several limitations. First, although it assesses surgical approaches to the mitral valve, it does not evaluate the strategy of revascularization alone. Given current guidelines, there was lack of equipoise to randomly assign patients with severe mitral regurgitation to a CABG-only group. However, there is equipoise for the randomization of patients with moderate ischemic mitral regurgitation to revascularization alone, and such a CTSN trial is ongoing (ClinicalTrials.gov number, NCT00806988). Second, the primary end point was an echocardiographic measure of left ventricular remodeling, not a clinical outcome such as survival. However, a randomized trial with a 1-year mortality end point would have required more than 4000 patients, exceeding our capacity for timely enrollment. Our choice of the LVESVI as the primary end point was driven by strong evidence correlating the LVESVI with clinical outcomes, including the NYHA class and rates of hospitalization and survival. ${ }^{34-40}$ Third, the use of transthoracic echocardiography for measuring recurrent mitral regurgitation may underestimate the degree of mitral regurgitation in patients with prosthetic valves. However, the transmitral gradient, and thus the inflow velocity, that were observed in these patients were within normal ranges, which suggests no substantial mitral regurgitation. Finally, we report here on a relatively short follow-up period of 12 months, although follow-up will continue for 24 months. 
Recently, the field has embraced mitral-valve repair over replacement, without a strong evidence base. According to 2008-2012 data from the Society of Thoracic Surgeons, 66\% of mitral-valve surgeries in patients undergoing CABG used a repair approach. ${ }^{41}$ However, our comparison between chordal-sparing mitral-valve replacement and repair in patients with severe ischemic mitral regurgitation did not show significant differences. This conclusion is based on the absence of a significant difference in left ventricular reverse remodeling and in the rate of major adverse cardiac or cerebrovascular events at 12 months. Mitral-valve replacement provides a considerably more durable correction of mitral regurgitation, which may have an important effect on long-term outcomes. However, this factor must be weighed against any potential adverse consequences of a prosthetic valve. Further patient follow-up is needed to confirm the findings of this trial; such follow-up may lead to the identification of predictors of recurrence of mitral regurgitation to allow for a more appropriate selection of patients.

\section{Supplementary Material}

Refer to Web version on PubMed Central for supplementary material.

\section{Acknowledgments}

Supported by a cooperative agreement (U01 HL088942) with the National Heart, Lung, and Blood Institute and the National Institute of Neurological Diseases and Stroke, National Institutes of Health, and by the Canadian Institutes of Health Research.

\section{Appendix}

The authors' affiliations are as follows: the Department of Surgery, Division of Cardiovascular Surgery, University of Pennsylvania School of Medicine, Philadelphia (M.A.A., Y.J.W.); the International Center for Health Outcomes and Innovation Research (InCHOIR), Department of Health Evidence and Policy, Mount Sinai School of Medicine (M.K.P., A.J.M., A.C.G., D.D.A., E.B., E.G.M.), Division of Cardiothoracic Surgery, Department of Surgery, College of Physicians and Surgeons, Columbia University (M.A.), and the Department of Cardiothoracic Surgery, Montefiore Medical Center and Albert Einstein College of Medicine (D.A.D., R.E.M.) — all in New York; Montreal Heart Institute, University of Montreal, Montreal (L.P.P.); Institut Universitaire de Cardiologie de Québec, Hôpital Laval, Quebec, QC, Canada (P.V., F.D.); the Division of Cardiovascular and Thoracic Surgery, Department of Surgery, Duke University Medical Center, Durham (P.K.S.), and the Department of Cardiovascular Sciences, East Carolina Heart Institute at East Carolina University, Greenville (T.B.F.) — both in North Carolina; Echocardiography Core Lab, Massachusetts General Hospital (J.W.H.), and Cardiovascular Division, Brigham and Women's Hospital (P.T.O.) - both in Boston; the Department of Thoracic and Cardiovascular Surgery, Cleveland Clinic Foundation, Cleveland (E.H.B.); Clinical Research Unit, Division of Cardiothoracic Surgery, Emory University School of Medicine, Atlanta (J.D.P.); Division of Cardiac Surgery, University of Maryland School of Medicine, Baltimore (J.S.G.); Baylor Research Institute, Dallas (M.M.); National Institutes of Health (NIH) Heart Center at Suburban Hospital (K.A.H.), and the Office of Biostatistics Research (N.L.G.) and the Division of Cardiovascular Sciences (M.A.M.), NIH - all in Bethesda, 
MD; the Division of Thoracic and Cardiovascular Surgery, University of Virginia School of Medicine, Charlottesville (G.A., I.L.K.); and the Center for Heart and Vascular Health, Christiana Care Health System, Newark, DE (T.J.G.).

\section{References}

1. Lamas GA, Mitchell GF, Flaker GC, et al. Clinical significance of mitral regurgitation after acute myocardial infarction. Circulation. 1997; 96:827-833. [PubMed: 9264489]

2. Grigioni F, Enriquez-Sarano M, Zehr KJ, Bailey KR, Tajik AJ. Ischemic mitral regurgitation: longterm outcome and prognostic implications with quantitative Doppler assessment. Circulation. 2001; 103:1759-1764. [PubMed: 11282907]

3. Ellis SG, Whitlow PL, Raymond RE, Schneider JP. Impact of mitral regurgitation on long-term survival after percutaneous coronary intervention. Am J Cardiol. 2002; 89:315-318. [PubMed: 11809433]

4. Di Salvo TG, Acker MA, Dec GW, Byrne JG. Mitral valve surgery in advanced heart failure. J Am Coll Cardiol. 2010; 55:271-282. [PubMed: 20117430]

5. Bonow RO, Carabello BA, Kanu C, et al. ACC/AHA 2006 guidelines for the management of patients with valvular heart disease: a report of the American College of Cardiology/American Heart Association Task Force on Practice Guidelines (writing committee to revise the 1998 Guidelines for the Management of Patients with Valvular Heart Disease): developed in collaboration with the Society of Cardiovascular Anesthesiologists: endorsed by the Society for Cardiovascular Angiography and Interventions and the Society of Thoracic Surgeons. Circulation. 2006; 114(5):e84-e231. [Errata, Circulation 2007; 115(15): e409, 2010; 121(23): e443.]. [PubMed: 16880336]

6. The Joint Task Force on the Management of Valvular Heart Disease of the European Society of Cardiology and the European Association for Cardio-Thoracic Surgery. Guidelines on the management of valvular heart disease (version 2012). Eur Heart J. 2012; 33:2451-2496. [PubMed: 22922415]

7. Gillinov AM, Wierup PN, Blackstone EH, et al. Is repair preferable to replacement for ischemic mitral regurgitation? J Thorac Cardiovasc Surg. 2001; 122:1125-1141. [PubMed: 11726887]

8. Grossi EA, Goldberg JD, LaPietra A, et al. Ischemic mitral valve reconstruction and replacement: comparison of long-term survival and complications. J Thorac Cardiovasc Surg. 2001; 122:11071124. [PubMed: 11726886]

9. Reece TB, Tribble CG, Ellman PI, et al. Mitral repair is superior to replacement when associated with coronary artery disease. Ann Surg. 2004; 239:671-675. [PubMed: 15082971]

10. Al-Radi OO, Austin PC, Tu JV, David TE, Yau TM. Mitral repair versus replacement for ischemic mitral regurgitation. Ann Thorac Surg. 2005; 79:1260-1267. [PubMed: 15797060]

11. Zoghbi WA, Enriquez-Sarano M, Foster E, et al. Recommendations for evaluation of the severity of native valvular regurgitation with two-dimensional and Doppler echocardiography. J Am Soc Echocardiogr. 2003; 16:777-802. [PubMed: 12835667]

12. Perrault LP, Moskowitz AJ, Kron IL, et al. Optimal surgical management of severe ischemic mitral regurgitation: to repair or to replace? J Thorac Cardiovasc Surg. 2012; 143:1396-1403. [PubMed: 22054660]

13. Bax JJ, Braun J, Somer ST, et al. Restrictive annuloplasty and coronary revascularization in ischemic mitral regurgitation results in reverse left ventricular remodeling. Circulation. 2004; 110(Suppl 1):II-103-II-108. [PubMed: 15364847]

14. Yiu SF, Enriquez-Sarano M, Tribouilloy C, Seward JB, Tajik AJ. Determinants of the degree of functional mitral regurgitation in patients with systolic left ventricular dysfunction: a quantitative clinical study. Circulation. 2000; 102:1400-1406. [PubMed: 10993859]

15. Kang DH, Kim MJ, Kang SJ, et al. Mitral valve repair versus revascularization alone in the treatment of ischemic mitral regurgitation. Circulation. 2006; 114(Suppl):I-499-I-503. [PubMed: 16820626] 
16. O’Brien PC, Fleming TR. A multiple testing procedure for clinical trials. Biometrics. 1979; 35:549-556. [PubMed: 497341]

17. Lan KKG, DeMets DL. Discrete sequential boundaries for clinical trials. Biometrika. 1983; 70:659-663.

18. Gammie JS, Sheng S, Griffith BP, et al. Trends in mitral valve surgery in the United States: results from the Society of Thoracic Surgeons Adult Cardiac Surgery Database. Ann Thorac Surg. 2009; 87:1431-1437. [PubMed: 19379881]

19. Solomon SD, Skali H, Anavekar NS, et al. Changes in ventricular size and function in patients treated with valsartan, captopril, or both after myocardial infarction. Circulation. 2005; 111:34113419. [PubMed: 15967846]

20. Di Donato M, Castelvecchio S, Menicanti L. End-systolic volume following surgical ventricular reconstruction impacts survival in patients with ischaemic dilated cardiomyopathy. Eur J Heart Fail. 2010; 12:375-381. [PubMed: 20185429]

21. Mann DL, Bristow MR. Mechanisms and models in heart failure: the biomechanical model and beyond. Circulation. 2005; 111:2837-2849. [Erratum, Circulation 2005; 112(4): e75.]. [PubMed: 15927992]

22. Society of Thoracic Surgeons. Adult cardiac surgery database: executive summary: Harvest 1. 2013. (http://www.sts.org/sites/default/files/documents/1stHarvestExecutiveSummary.pdf).

23. Thourani VH, Weintraub WS, Guyton RA, et al. Outcomes and long-term survival for patients undergoing mitral valve repair versus replacement: effect of age and concomitant coronary artery bypass grafting. Circulation. 2003; 108:298-304. [PubMed: 12835220]

24. Micovic S, Milacic P, Otasevic P, et al. Comparison of valve annuloplasty and replacement for ischemic mitral valve incompetence. Heart Surg Forum. 2008; 11:E340-E345. [PubMed: 19073530]

25. Milano CA, Daneshmand MA, Rankin JS, et al. Survival prognosis and surgical management of ischemic mitral regurgitation. Ann Thorac Surg. 2008; 86:735-744. [PubMed: 18721554]

26. Silberman S, Oren A, Klutstein MW, et al. Does mitral valve intervention have an impact on late survival in ischemic cardiomyopathy? Isr Med Assoc J. 2006; 8:17-20. [PubMed: 16450745]

27. Vassileva CM, Boley T, Markwell S, Hazelrigg S. Meta-analysis of short-term and long-term survival following repair versus replacement for ischemic mitral regurgitation. Eur J Cardiothorac Surg. 2011; 39:295-303. [PubMed: 20727782]

28. Magne J, Girerd N, Sénéchal M, et al. Mitral repair versus replacement for ischemic mitral regurgitation: comparison of short-term and long-term survival. Circulation. 2009; 120(Suppl):S104-S111. [PubMed: 19752354]

29. McGee EC, Gillinov AM, Blackstone EH, et al. Recurrent mitral regurgitation after annuloplasty for functional ischemic mitral regurgitation. J Thorac Cardiovasc Surg. 2004; 128:916-924. [PubMed: 15573077]

30. Magne J, Sénéchal M, Dumesnil JG, Pibarot P. Ischemic mitral regurgitation: a complex multifaceted disease. Cardiology. 2009; 112:244-259. [PubMed: 18758181]

31. Hung J, Papakostas L, Tahta SA, et al. Mechanism of recurrent ischemic mitral regurgitation after annuloplasty: continued LV remodeling as a moving target. Circulation. 2004; 110(Suppl 1):II-185-II-190.

32. Levine RA, Schwammenthal E. Ischemic mitral regurgitation on the threshold of a solution: from paradoxes to unifying concepts. Circulation. 2005; 112:745-758. [PubMed: 16061756]

33. Bouchard D, Jensen H, Carrier M, et al. Effect of systematic downsizing rigid ring annuloplasty in patients with moderate ischemic mitral regurgitation. J Thorac Cardiovasc Surg. 2013

34. Konstam MA, Udelson JE, Anand IS, Cohn JN. Ventricular remodeling in heart failure: a credible surrogate endpoint. J Card Fail. 2003; 9:350-353. [PubMed: 14583894]

35. Carson P, Tognoni G, Cohn JN. Effect of valsartan on hospitalization: results from Val-HeFT. J Card Fail. 2003; 9:164-171. [PubMed: 12815565]

36. Kramer DG, Trikalinos TA, Kent DM, Antonopoulos GV, Konstam MA, Udelson JE. Quantitative evaluation of drug or device effects on ventricular remodeling as predictors of therapeutic effects on mortality in patients with heart failure and reduced ejection fraction: a meta-analytic approach. J Am Coll Cardiol. 2010; 56:392-406. [PubMed: 20650361] 
37. White HD, Norris RM, Brown MA, Brandt PW, Whitlock RM, Wild CJ. Left ventricular endsystolic volume as the major determinant of survival after recovery from myocardial infarction. Circulation. 1987; 76:44-51. [PubMed: 3594774]

38. St John Sutton M, Pfeffer MA, Moye L, et al. Cardiovascular death and left ventricular remodeling two years after myocardial infarction: baseline predictors and impact of long-term use of captopril: information from the Survival and Ventricular Enlargement (SAVE) trial. Circulation. 1997; 96:3294-3299. [PubMed: 9396419]

39. Moss AJ, Hall WJ, Cannom DS, et al. Cardiac-resynchronization therapy for the prevention of heart-failure events. N Engl J Med. 2009; 361:1329-1338. [PubMed: 19723701]

40. Ghio S, Freemantle N, Scelsi L, et al. Long-term left ventricular reverse remodelling with cardiac resynchronization therapy: results from the CARE-HF trial. Eur J Heart Fail. 2009; 11:480-488. [PubMed: 19287017]

41. Years 2008-2012: the Adult Cardiac Surgery Database. Chicago: Society of Thoracic Surgeons; (http://www.sts.org/national-database). 


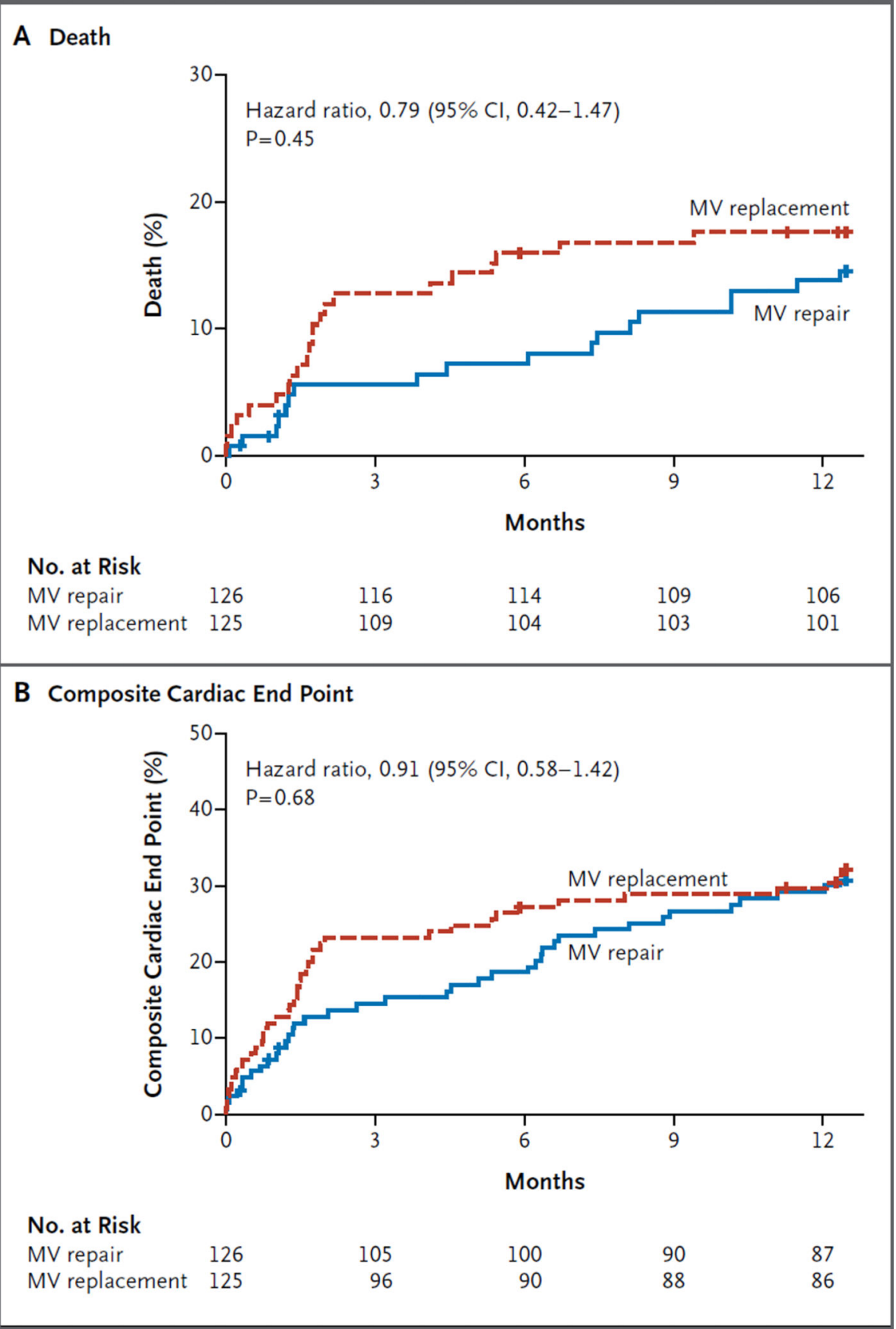

Figure 1. Rates of Death and the Composite Cardiac End Point

The composite end point of the rate of major adverse cardiac or cerebrovascular events included death, stroke, subsequent mitral-valve (MV) surgery, hospitalization for heart failure, and an increase in the New York Heart Association class of 1 or more. Crosses indicate that patients' data were censored at that point. 


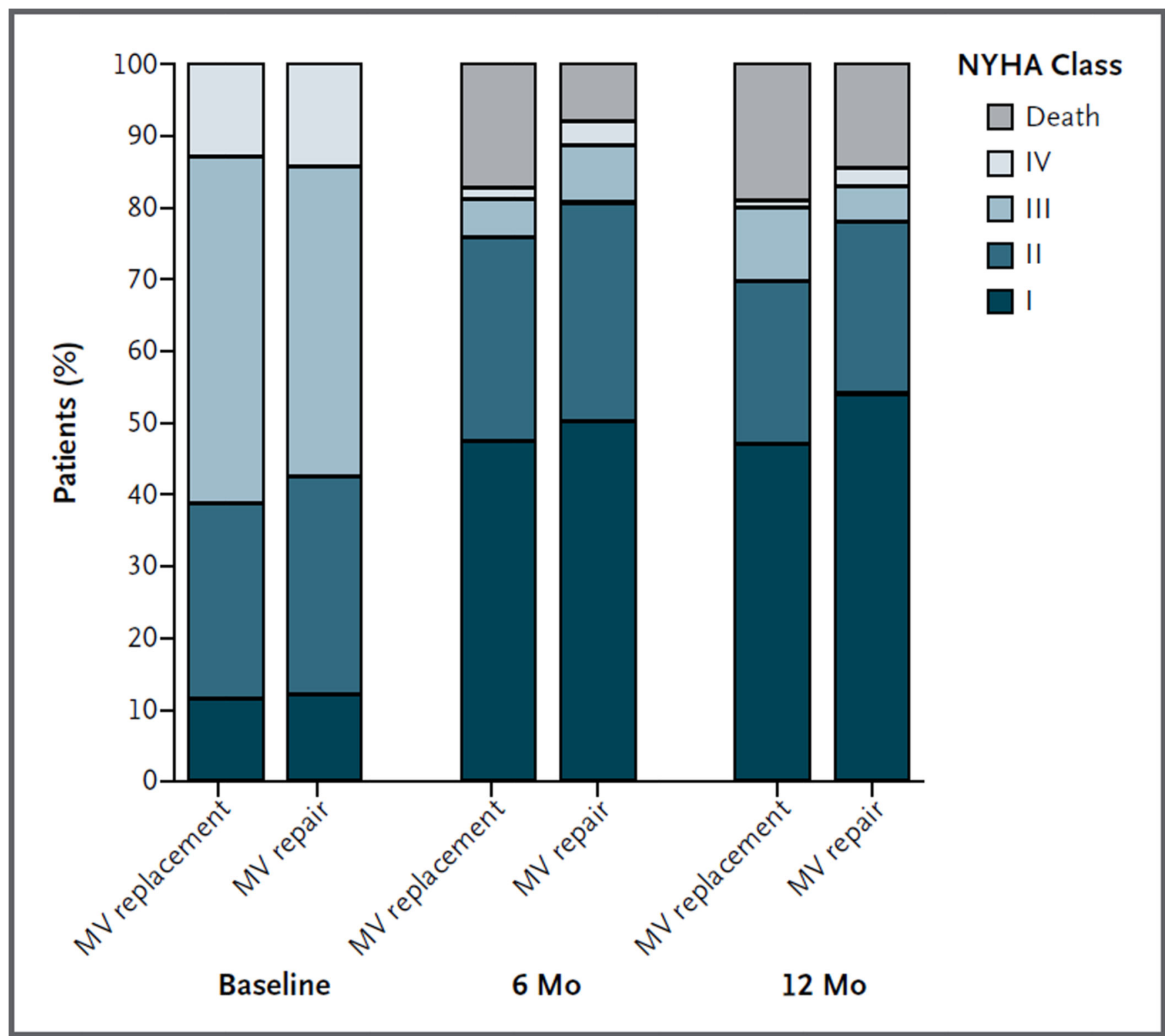

Figure 2. Rates of New York Heart Association Class and Death at Baseline, 6 Months, and 12 Months 


\section{Table 1}

Baseline and Operative Characteristics of the Patients. ${ }^{*}$

\begin{tabular}{|c|c|c|c|}
\hline Characteristic & $\begin{array}{l}\text { Repair Group } \\
\quad(\mathbf{N}=\mathbf{1 2 6})\end{array}$ & $\begin{array}{l}\text { Replacement Group } \\
\qquad(\mathbf{N}=\mathbf{1 2 5})\end{array}$ & $P$ Value \\
\hline Male sex - no. $(\%)$ & $77(61.1)$ & $78(62.4)$ & 0.83 \\
\hline Age - yr & $69 \pm 10$ & $68 \pm 9$ & 0.36 \\
\hline White race - no. $(\%)^{\dagger}$ & $104(82.5)$ & $98(78.4)$ & 0.40 \\
\hline Hispanic ethnic group - no. $(\%)^{\dagger}$ & $13(10.3)$ & $11(8.8)$ & 0.68 \\
\hline \multicolumn{4}{|l|}{ Medical and surgical history — no. (\%) } \\
\hline Diabetes & $48(38.1)$ & $41(32.8)$ & 0.41 \\
\hline Renal insufficiency & $29(23.0)$ & $40(32.0)$ & 0.11 \\
\hline Previous CABG & $24(19.0)$ & $23(18.4)$ & 0.90 \\
\hline Previous PCI & $50(39.7)$ & $40(32.0)$ & 0.20 \\
\hline Heart failure & $88(69.8)$ & $92(73.6)$ & 0.51 \\
\hline Myocardial infarction & 99 (78.6) & $88(70.4)$ & 0.14 \\
\hline Atrial fibrillation & $45(35.7)$ & $35(28.0)$ & 0.19 \\
\hline Implantable cardioverter-defibrillator & $23(18.3)$ & $17(13.6)$ & 0.31 \\
\hline Stroke & $14(11.1)$ & $11(8.8)$ & 0.54 \\
\hline Left ventricular ejection fraction - $\%$ & $42.4 \pm 12.0$ & $40.0 \pm 11.0$ & 0.10 \\
\hline Effective regurgitant orifice area $-\mathrm{cm}^{2}$ & $0.40 \pm 0.17$ & $0.39 \pm 0.11$ & 0.64 \\
\hline Grade on CCS angina scale - no. $(\%)^{\frac{\xi}{F}}$ & & & 0.19 \\
\hline No angina & $57(45.2)$ & $70(56.0)$ & \\
\hline Grade III or IV & $31(24.6)$ & $21(16.8)$ & \\
\hline NYHA class III or IV — no./total no. $(\%)^{\S}$ & $72 / 125(57.6)$ & $76 / 124(61.3)$ & 0.55 \\
\hline Minnesota Living with Heart Failure score ${ }^{q l}$ & $46.1 \pm 27.2$ & $50.0 \pm 27.4$ & 0.29 \\
\hline \multicolumn{4}{|l|}{ Concomitant procedure - no. $(\%)$} \\
\hline CABG & $93(73.8)$ & $94(75.2)$ & 0.80 \\
\hline Tricuspid-valve repair & $16(12.7)$ & $22(17.6)$ & 0.28 \\
\hline Atrial maze & $15(11.9)$ & $16(12.8)$ & 0.83 \\
\hline
\end{tabular}

* Plus-minus values are means \pm SD. CABG denotes coronary-artery bypass grafting, and PCI percutaneous coronary intervention.

${ }^{\dagger}$ Race or ethnic group was self-reported.

* Grades III or IV for the Canadian Cardiovascular Society (CCS) classification of angina are as follows: grade III, marked limitation of ordinary physical activity, with walking one or two blocks on the level and climbing one flight of stairs in normal conditions and at normal pace; grade IV, inability to carry on any physical activity without discomfort, and anginal syndrome may be present at rest.

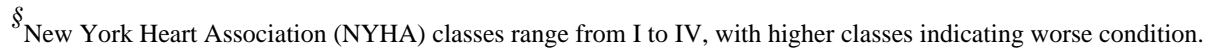

${ }^{I}$ Scores on the Minnesota Living with Heart Failure questionnaire range from 0 to 105, with higher scores indicating worse condition. 


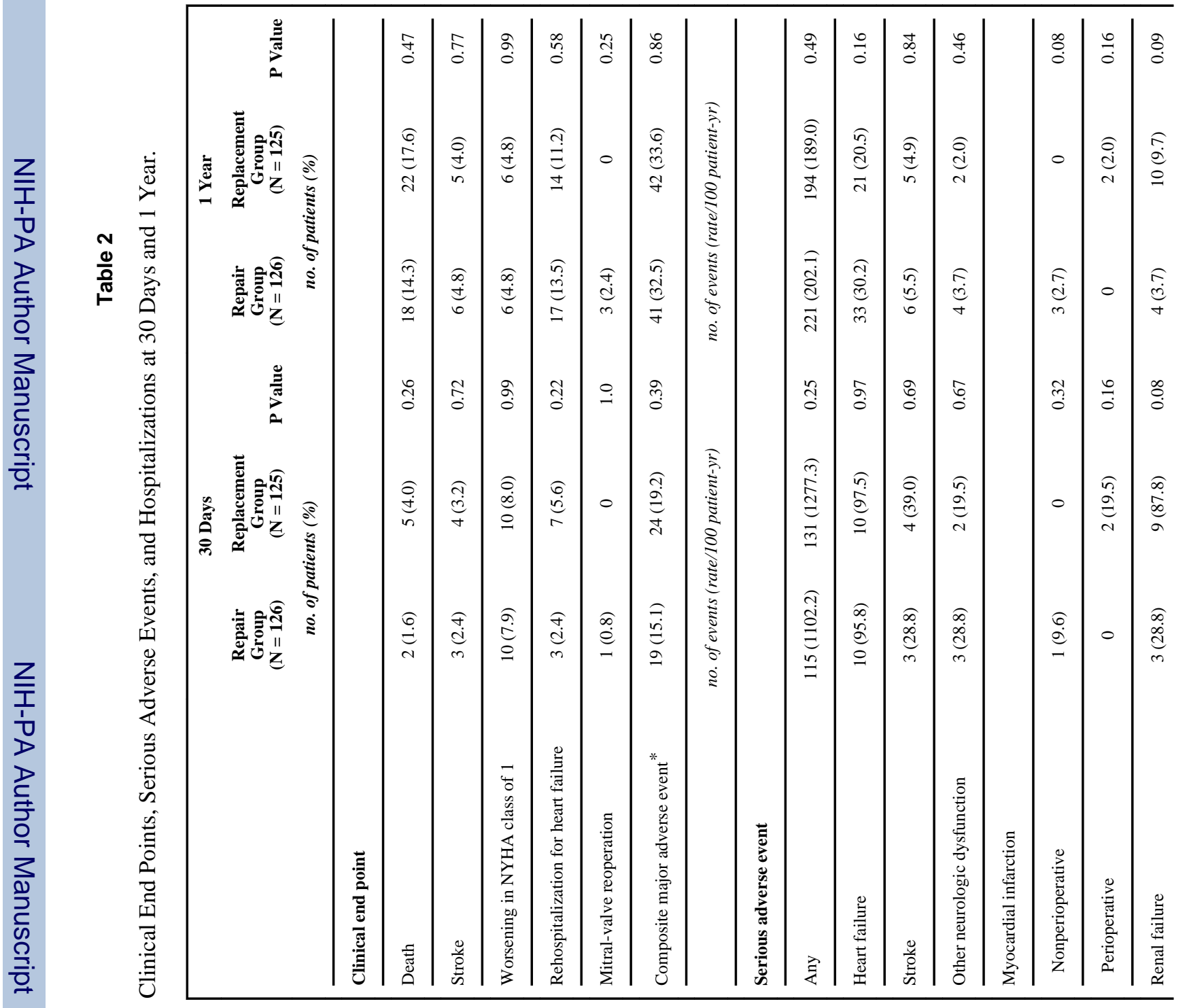




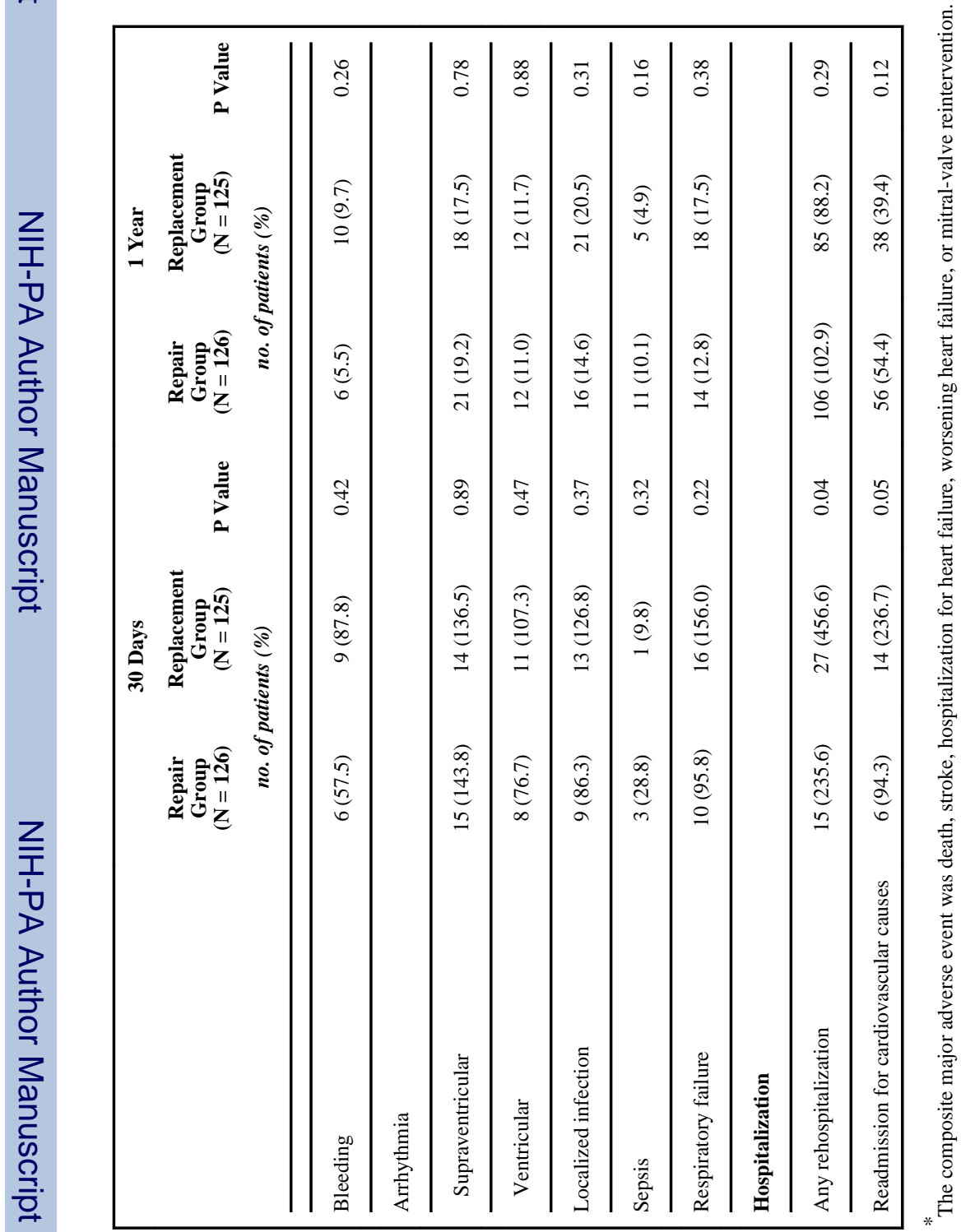

N Engl J Med. Author manuscript; available in PMC 2014 August 11. 
Table 3

Quality of Life and Functional Status of Patients at 1 Year. $^{*}$

\begin{tabular}{|c|c|c|c|}
\hline Scale & Repair Group & Replacement Group & P Value \\
\hline \multicolumn{4}{|l|}{$\mathrm{SF}-12^{\dagger}$} \\
\hline Physical function & & & 0.63 \\
\hline Score & $43.6 \pm 8.1$ & $44.2 \pm 7.1$ & \\
\hline Patients evaluated — no./total no. (\%) & $93 / 105(88.6)$ & $85 / 102(83.3)$ & \\
\hline Mental function & & & 0.92 \\
\hline Score & $46.8 \pm 7.1$ & $46.9 \pm 6.4$ & \\
\hline Patients evaluated — no./total no. (\%) & $93 / 105(88.6)$ & $85 / 102(83.3)$ & \\
\hline Minnesota Living with Heart Failure questionnaire & & & 0.12 \\
\hline Score & $24.5 \pm 23.1$ & $19.6 \pm 19.4$ & \\
\hline Patients evaluated - no./total no. $(\%)$ & 95/105 (90.5) & $85 / 102(83.3)$ & \\
\hline EQ-5D & & & 0.97 \\
\hline Score & $73.7 \pm 16.3$ & $73.9 \pm 20.1$ & \\
\hline Patients evaluated - no./total no. $(\%)$ & $91 / 105(86.7)$ & $80 / 102(78.4)$ & \\
\hline NYHA class - no./total no. $(\%)$ & & & 0.28 \\
\hline All classes & $100 / 105(95.2)$ & 93/102 (91.2) & \\
\hline Class III or IV & $9 / 100(9.0)$ & $13 / 93(14.0)$ & \\
\hline CCS classification - no./total no. $(\%)$ & & & 0.42 \\
\hline All classes & 96/105 (91.4) & $89 / 102(87.3)$ & \\
\hline Class III or IV & $3 / 96(3.1)$ & $2 / 89(2.2)$ & \\
\hline
\end{tabular}

Plus-minus values are means \pm SD.

${ }^{\dagger}$ Scores on the Medical Outcomes Study 12-Item Short Form Health Survey (SF-12) range from 0 to 100, with higher scores indicating a better outcome.

${ }^{*}$ Scores on the EuroQol Group 5-Dimension Self-Report Questionnaire (EQ-5D) range from 0 to 100, with higher scores indicating a better quality of life. 